\title{
Bacmid Expression of Granulovirus Enhancin En3 Accumulates in Cell Soluble Fraction to Potentiate Nucleopolyhedrovirus Infection
}

\author{
Adriana Ricarte-Bermejo ${ }^{1}$, Oihane Simón ${ }^{1, *}$, Ana Beatriz Fernández ${ }^{1,2}$, Trevor Williams ${ }^{3}$ \\ and Primitivo Caballero ${ }^{1,2}$ \\ 1 Institute for Multidisciplinary Research in Applied Biology, Universidad Pública de Navarra, \\ 31006 Pamplona, Navarra, Spain; adriana.ricarte@unavarra.es (A.R.-B.); \\ anabeatriz.fernandez@unavarra.es (A.B.F.); pcm92@unavarra.es (P.C.) \\ 2 Departamento de Investigación y Desarrollo, Bioinsectis SL, Polígono Industrial Mocholi Plaza Cein 5, \\ Nave A14, 31110 Noain, Navarra, Spain \\ 3 Instituto de Ecología AC, Xalapa, Veracruz 91073, Mexico; trevor.williams@inecol.mx \\ * Correspondence: oihane.simon@unavarra.es; Tel.: +34-948168012
}

check for updates

Citation: Ricarte-Bermejo, A.; Simón, O.; Fernández, A.B.; Williams, T.; Caballero, P. Bacmid Expression of Granulovirus Enhancin En3 Accumulates in Cell Soluble Fraction to Potentiate Nucleopolyhedrovirus Infection. Viruses 2021, 13, 1233. https://doi.org/10.3390/v13071233

Academic Editor:

Miguel López-Ferber

Received: 31 May 2021

Accepted: 22 June 2021

Published: 25 June 2021

Publisher's Note: MDPI stays neutral with regard to jurisdictional claims in published maps and institutional affiliations.

Copyright: (c) 2021 by the authors. Licensee MDPI, Basel, Switzerland. This article is an open access article distributed under the terms and conditions of the Creative Commons Attribution (CC BY) license (https:// creativecommons.org/licenses/by/ $4.0 /)$.
Abstract: Enhancins are metalloproteinases that facilitate baculovirus infection in the insect midgut. They are more prevalent in granuloviruses (GVs), constituting up to $5 \%$ of the proteins of viral occlusion bodies (OBs). In nucleopolyhedroviruses (NPVs), in contrast, they are present in the envelope of the occlusion-derived virions (ODV). In the present study, we constructed a recombinant Autographa californica NPV (AcMNPV) that expressed the Trichoplusia ni GV (TnGV) enhancin 3 (En3), with the aim of increasing the presence of enhancin in the OBs or ODVs. En3 was successfully produced but did not localize to the OBs or the ODVs and accumulated in the soluble fraction of infected cells. As a result, increased OB pathogenicity was observed when OBs were administered in mixtures with the soluble fraction of infected cells. The mixture of OBs and the soluble fraction of Sf9 cells infected with BacPhEn3 recombinant virus was $\sim 3$ - and $\sim 4$.7-fold more pathogenic than $\mathrm{BacPh}$ control OBs in the second and fourth instars of Spodoptera exigua, respectively. In contrast, when purified, recombinant $\mathrm{BacPhEn} 3 \mathrm{OBs}$ were as pathogenic as control $\mathrm{BacPh}$ OBs. The expression of En3 in the soluble fraction of insect cells may find applications in the development of virus-based insecticides with increased efficacy.

Keywords: Alphabaculovirus; Betabaculovirus; enhancins; AcMNPV recombinant; Spodoptera exigua; potentiation of pathogenicity

\section{Introduction}

Enhancins are virus-encoded metalloproteinases that can enhance the establishment of baculovirus infection by degrading the peritrophic matrix (PM) in the midgut of the host insect. They act as a protease and degrade the insect intestinal mucin (IIM), the major mucinous protein that constitutes the PM, resulting in the disruption of this structure and increasing its permeability to baculovirus occlusion-derived virions (ODVs) [1-6].

Enhancin genes are prevalent in lepidopteran-infecting granuloviruses (GV, genus Betabaculovirus), where they are present in the occlusion body (OB) matrix [5,6]. The virusenhancing activity of betabaculovirus enhancins has been well-documented [6-12]. In contrast, orthologues present in lepidopteran-infecting nucleopolyhedroviruses (NPV, genus Alphabaculovirus) are associated with ODV envelopes and their efficacy as enhancers of NPV infections has come from experiments with recombinant viruses [6,13-15]. Some betabaculovirus and alphabaculovirus genomes contain multiple copies of these genes [13-16].

Most of the studies on infection potentiation by betabaculovirus enhancins have been performed using enhancins purified from OBs [7-10,12,17], whereas others have employed bacmid technology to express enhancin genes in recombinant NPVs $[10,18-21]$. 
One question concerning the recombinant enhancin expressed by an NPV is whether the recombinant enzyme is occluded within OBs, as in GVs, or integrated into the ODV envelope, as occurs in NPVs. Previous studies in which the Trichoplusia ni GV (TnGV) enhancin gene was expressed in recombinant Autographa californica NPV (AcMNPV) did not specifically address the localization of the recombinant protein $[10,18,19]$. For example, TnGV enhancin purified from cells infected by a recombinant AcMNPV effectively degraded PM proteins and increased lethal infection in host larvae [10]. Others have suggested that the enhancin may be occluded within OBs, as recombinant OBs were significantly more pathogenic than wild-type OBs in larval bioassays $[18,19]$.

Interestingly, the incorporation of a betabaculovirus enhancin into alphabaculovirus OBs was achieved by fusing the enhancin gene to a C-terminal section of the polyhedrin gene $[20,21]$. Using this technology, a recombinant AcMNPV bacmid was constructed that embedded both Agrotis segetum GV enhancin and the Cydia pomonella GV GP37 enhancing factor within the OBs [20]. The GP37 enhancing factor is homologous to fusolin found in entomopoxviruses that binds chitin and enhances viral infection [22]. These recombinant viruses produced normal OBs that were significantly more pathogenic to susceptible larvae than wild-type OBs [20,21]. It is unclear, however, whether enhancin can be occluded into OBs or enveloped in the ODVs of an NPV without the use of the polyhedrin fusion technique.

The main objective of the present study was to determine whether an unmodified betabaculovirus enhancin, not fused with polyhedrin, was incorporated within NPV OBs or enveloped in the ODVs. For this, a polyhedrin-positive recombinant AcMNPV expressing a betabaculovirus enhancin was constructed. The localization of the recombinant protein was investigated by SDS-PAGE analyses and the insecticidal activity of the recombinant OBs was compared with that of wild-type OBs.

\section{Materials and Methods}

\subsection{Insects, Cells and Viruses}

Larvae of Spodoptera exigua were obtained from a healthy laboratory colony maintained on a semi-synthetic diet [23] at $25 \pm 1{ }^{\circ} \mathrm{C}$. Sf9 cells (ThermoFisher Scientific, Waltham, MA, USA) were maintained in TC100 medium (Lonza Bioscience, Cologne, Germany) supplemented with $10 \%$ fetal calf serum (Lonza Bioscience, Cologne, Germany) at $28 \pm 1{ }^{\circ} \mathrm{C}$ [24]. For the construction of the recombinant virus expressing the enhancin gene, the Bac-to-Bac ${ }^{\mathrm{TM}}$ Baculovirus Expression System was used (ThermoFisher Scientific, Waltham, MA, USA). The enhancin gene was amplified from Trichoplusia ni granulovirus (TnGV) [16], whereas the polyhedrin gene was amplified from the AcMNPV C6 clone, the type species of the Alphabaculovirus genus [25]. All viruses were obtained from the virus collection of the Microbial Bioinsecticides group at the Universidad Pública de Navarra.

\subsection{Recombinant BacPh and BacPhEn3 Virus DNAs}

We selected enhancin 3 (En3) of TnGV to construct the recombinant virus as TnGVpurified enhancins produced the highest potentiation (discussed in Appendix A). Among the three enhancins present in the TnGV genome [16], En3 possesses both the zinc-binding domain of metalloproteinases and the mucin-binding domain (Figure S1) (explained in Appendix B).

The recombinant virus was constructed using a Bac-to-Bac recombination system (ThermoFisher Scientific, Waltham, MA, USA) [26]. Two primer sets were designed to amplify the full-length coding sequence (from ATG to stop) of the enhancin 3 gene (en3, viral enhancing factor 3) of TnGV (TnOrf-149; nt 153,610 to 156,315 in the TnGV genome; accession number KU752557 or NC_038375), and the polyhedrin gene (ph) of AcMNPV (AcOrf-8; nt 4520 to 5257 in the AcMNPV-C6 genome; accession number L22858 or NC_001623) (Table 1). We did not include a His-tag sequence in the C-terminal for protein purification and detection, in order to produce a natural enhancin and to determine its natural location. Previously, the use of an N-terminal His-tag for identification and purification 
purposes resulted in reduced stability and binding properties of tagged proteins [27], and compromised the mucin degradation activity of the tagged enzyme in the case of enhancin-like Bel proteins from bacteria [28]. The genes were cloned in the pFastBacTM Dual (pFBD-phx-p10x) expression vector under the polyhedrin (en3 gene) and p10 (ph gene) promoters. For the insertion of the specific genes, two pairs of primers were designed to amplify the en 3 gene of TnGV and $p h$ of AcMNPV. The XbaI and PstI restriction sites were introduced near the $5^{\prime}$ termini of the forward and reverse primers of en3, respectively, for further cloning and to direct the transcription of the en 3 with the polyhedrin promoter. Additionally, downstream from the $\mathrm{XbaI}$ restriction site and upstream from the ATG codon, a $20 \mathrm{nt}$ sequence was inserted that corresponded to the en 3 promoter region, in order to transcribe this gene under its homologous promoter [10]. Similarly, for the ph gene, the XhoI and $\mathrm{NcoI}$ restriction sites were introduced near the $5^{\prime}$ termini of the forward and reverse primers, respectively, to direct cloning of the p10 promoter. The forward primer (Ph-Fw) was designed $308 \mathrm{nt}$ upstream of the ATG codon, to avoid an AT rich region $69 \%$ AT and $31 \%$ GC), as baculovirus intergenic regions are AT rich and the primer could otherwise anneal at different points across the genome.

Table 1. Primers used in this study.

\begin{tabular}{|c|c|c|}
\hline Primer & Sequence & Amplification Purpose \\
\hline En3-TnGV-Fw & 5'-TCTCTAGAGCTGCATTAATTATAAGACTATGTC -3 & $\begin{array}{l}\text { En3 amplification. TnGV DNA was used } \\
\text { a template. Underlined-the XbaI site. } \\
\text { Double underlined-En3 promoter and } \\
\text { ATG start codon; nt } 153,590 \text { to } 153,614 \text { in } \\
\text { the TnGV genome. Tm } 51^{\circ} \mathrm{C} \text {. }\end{array}$ \\
\hline En3-TnGV-Rv & 5'-CCCTGCAGTTAGAACGCTATCATTTTTAACG-3 & $\begin{array}{c}\text { En3 amplification. TnGV DNA was used } \\
\text { a template. Underlined-the PstI site. } \\
\text { Double underlined - the en3 TAA stop } \\
\text { codon; nt } 156,293 \text { to } 156,315 \text { in TnGV } \\
\text { genome. Tm } 50{ }^{\circ} \mathrm{C} \text {. }\end{array}$ \\
\hline $\mathrm{Ph}-\mathrm{Fw}$ & 5'-CGCTCGAGGCCGGCATAGTACGC-3' & $\begin{array}{c}\text { Ph amplification. AcMNPV C6 DNA was } \\
\text { used a template. Underlined-the XhoI } \\
\text { site; nt } 4197 \text { to } 4211 \text { in AcMNPV genome. } \\
\operatorname{Tm} 56{ }^{\circ} \mathrm{C} \text {. }\end{array}$ \\
\hline $\mathrm{Ph}-\mathrm{Rv}$ & $5^{\prime}$-CGCCATGGTTAATACGCCGGACCAGTG-3' & $\begin{array}{l}\text { Ph amplification. AcMNPV C6 DNA was } \\
\text { used a template. Underlined-the NcoI } \\
\text { site. Double underlined-the ph TAA } \\
\text { stop codon; nt } 5239 \text { to } 5257 \text { in AcMNPV } \\
\text { genome. Tm } 54^{\circ} \mathrm{C} \text {. }\end{array}$ \\
\hline En3-Seq-Fw & $5^{\prime}$-CCGTACCCGCAAATATG-3' & $\begin{array}{l}\text { En3 sequence confirmation. Primer that } \\
\text { annealed at nt } 1053 \text { to } 1073 \text { in the en3 } \\
\text { gene. } \operatorname{Tm} 53^{\circ} \mathrm{C} \text {. }\end{array}$ \\
\hline pFBD-seq-Fw & 5'-CCGTGTTTCAGTTAGCC-3' & $\begin{array}{c}\text { En3 sequence confirmation. Primer that } \\
\text { annealed at nt } 7563 \text { to } 7579 \text { in pFBD } \\
\text { plasmid. Tm } 54^{\circ} \mathrm{C} \text {. }\end{array}$ \\
\hline M13-Fw & 5'-CCCAGTCACGACGTTGTAAAACG-3' & $\begin{array}{l}\text { For confirmation of correct insertion of } \\
\text { en } 3 \text { and ph. Primer that flanked the mini } \\
\text { att-Tn7 site of the bacmid. Tm } 54{ }^{\circ} \mathrm{C} \text {. }\end{array}$ \\
\hline M13-Rv & 5'-AGCGGATAACAATTTCACACAGG-3' & $\begin{array}{l}\text { For confirmation of correct insertion of } \\
\text { en } 3 \text { and } p h \text {. Primer that flanked the mini } \\
\text { att-Tn7 site of the bacmid. Tm } 53^{\circ} \mathrm{C} \text {. }\end{array}$ \\
\hline
\end{tabular}

PCR amplifications were conducted using the Phusion high-fidelity Pfu DNA polymerase (New England Biolabs, Ipswich, MA, USA) and amplicons were recovered by using the PCR clean-up extraction kit NucleoSpin ${ }^{\circledR}$ Extract II Kit (Macherey-Nagel, Düren, 
Germany). The en3- and $p h$-purified products were then ligated into pJET1.2/blunt plasmid (CloneJET PCR Cloning Kit, ThermoFisher Scientific, Waltham, MA, USA) following the manufacturer's instructions. Ligation mixtures were transformed into Escherichia coli XL1-Blue electrocompetent cells using standard procedures. Positive clones were identified by colony-PCR. Five positive clones were grown, and plasmid DNAs were purified using the NucleoSpin R Plasmid Kit (Macherey-Nagel Inc., Düren, Germany). Subsequently, two selected plasmids for each gene were sequenced by ABI PRISM Big Dye Terminator Cycle Sequencing Ready Reaction Kits and an ABI PRISM 3100 Genetic Analyzer (STABVida, Caparica, Portugal). After sequence confirmation, a selected clone was digested with $\mathrm{XbaI}$ and PstI enzymes and electrophoresed in 1\% agarose gel. The generated restriction fragment was extracted from the gel and purified by column and ligated into XbaI-PstIdigested $\mathrm{pFBD}$ vector to generate the pFBD-En3. Two independent clones were selected for sequencing as described above. Once the correct insertion of en 3 was confirmed, the ph gene was cloned in the pFBD-En3 by double digestion with XhoI-NcoI to obtain the recombinant plasmid pFBD-PhEn3, under the control of the p10 promoter. Two independent clones were selected for sequencing to confirm the correct insertion of the $p h$ gene. Finally, ligation products were electroporated into E. coli DH10BacTM cells (ThermoFisher Scientific, Waltham, MA, USA) that contained the AcMNPV shuttle vector (bacmid) and the helper plasmid, to produce the recombinant bacmid BacPhEn3, following transposition of the pFBD-PhEn3 expression construct through the transposition of site-specific cassettes between Tn7R and Tn7L and the subsequent steps following standard protocols. In parallel, a negative control virus was constructed that included the $p h$ gene without any gene of interest, to generate the $\mathrm{pFBD}-\mathrm{Ph}$ vector, previously digested with XhoI-NcoI enzymes, under the $p 10$ promoter, following the same procedure.

Colonies were selected on LB (Luria Bertani) agar plates containing kanamycin $(50 \mu \mathrm{g} / \mathrm{mL})$, gentamycin $(7 \mu \mathrm{g} / \mathrm{mL})$, tetracycline $(10 \mu \mathrm{g} / \mathrm{mL}), X-g a l(100 \mu \mathrm{g} / \mathrm{mL})$ and IPTG $(40 \mu \mathrm{g} / \mathrm{mL})$. Ten white colonies were re-streaked on fresh LB agar plates under the same conditions to avoid contamination. Recombinant bacmid DNA was isolated using the PureLinkTM HiPure Plasmid DNA Miniprep Kit (ThermoFisher Scientific, Waltham, MA, USA). The successful transposition to bacmid was confirmed by digestion of DNA with PstI and by PCR amplification and sequence analysis using M13-Fw and M13-Rv primers that annealed outside the coding region of the $p 10$ and $p h$ promoters in the $\mathrm{pFBD}$ vector (Table 1).

\subsection{Transfection of Sf9 Cells with Recombinant BacPh and BacPhEn3 Virus DNAs}

Recombinant baculoviruses were produced in a $25 \mathrm{~cm}^{2}$ cell culture flask by transfecting $1 \mu \mathrm{g}$ of BacPhEn3 and BacPh genomic DNAs into $10^{6} \mathrm{Sf} 9$ cells using Lipofectin ${ }^{\circledR}$ Reagent (ThermoFisher Scientific, Waltham, MA, USA) [24,29]. The resulting OBs of both recombinant viruses were compared with those produced by the wild-type AcMNPV C6. For this, $10^{6}$ Sf9 cells were inoculated with AcMNPV-C6 budded virions (BVs) at a m.o.i. of 10 that we had in stock. The production of OBs in cells was checked daily, and five days post-infection, the supernatant containing BVs and the pellet containing the cells and viral OBs were recovered by centrifugation $(2400 \times g, 5 \mathrm{~min})$. DNA extraction was performed on infected cells [24] to confirm the restriction endonuclease (REN) profiles of the recombinant bacmids and to check for cross-contamination. Finally, to evaluate the normal occlusion of ODVs within the OBs of the two recombinants, the number of infectious units within OBs was compared with that of wild-type virus AcMNPV-C6 by end-point dilution in Sf9 cells [24,29]. Specifically, at five days post-infection, OBs were released from cells by sonication and OBs were counted in triplicate samples in a Neubauer hemocytometer. A $500 \mu \mathrm{L}$ volume of suspension containing $10^{8} \mathrm{OBs} / \mathrm{mL}$ was mixed with an equal volume of $0.1 \mathrm{M} \mathrm{Na}_{2} \mathrm{CO}_{3}$ and stirred at $28^{\circ} \mathrm{C}$ for $30 \mathrm{~min}$. Undissolved OBs and cell debris were removed by centrifugation $(5900 \times g, 5 \mathrm{~min})$, and the supernatant containing the ODVs was filtered through a $0.45 \mu \mathrm{m}$ filter and used in the end-point dilution assay [23,26]. 


\subsection{Production of BacPh and BacEn3 OBs in Larvae}

The BacPh and BacPhEn OBs were produced in larvae by injecting the BV suspension obtained from transfection assays. For this, BV suspensions were initially quantified by plaque assay $[24,29]$ and both suspensions had similar titers $\left(3.51 \times 10^{7} \mathrm{pfu} / \mathrm{mL}\right.$ for BacPh and $3.80 \times 10^{7} \mathrm{pfu} / \mathrm{mL}$ for BacPhEn3; $t=2.139 ;$ d.f. $=6 ; p=0.076$ ). Therefore, recombinant bacmid OBs were amplified by injecting the same quantity of BVs of BacPh and BacPhEn3, $8 \mu \mathrm{L}$ of BV suspension (1:1000), into S. exigua fifth instar larvae from the laboratory colony. Groups of 25 larvae were inoculated with each virus and were reared individually in $30 \mathrm{~mL}$ plastic cups with a piece of semi-synthetic diet. Virus-killed larvae were collected daily and transferred to a $50 \mathrm{~mL}$ collection tube. OBs were purified from dead larvae by filtration through muslin and several rounds of centrifugation in $0.1 \%(\mathrm{wt} / \mathrm{vol})$ sodium dodecyl sulfate (SDS) at $2400 \times \mathrm{g} 5 \mathrm{~min}$. Finally, OBs were resuspended in $1 \mathrm{~mL}$ doubledistilled water and stored at $4{ }^{\circ} \mathrm{C}$ until required. The fidelity of OBs produced in insects was confirmed by REN analysis and by sequencing of the PCR products obtained following amplification using M13-Fw and M13-Rv primers (Table 1).

\subsection{Detection and Localization of En3 Protein}

To detect and localize the TnGV En3 protein an SDS-PAGE was performed using different samples of cells and OBs produced both in cell culture and in larvae. The protocol to obtain the different samples was as follows. A $25 \mathrm{~cm}^{2}$ cell culture flask containing a batch of $10^{6}$ Sf9 cells was transfected with the DNAs of BacPh and BacPhEn3, as mentioned in Section 2.3. At five days post-infection, the Sf9 cells and medium were recovered with a cell scraper (Bio-Rad, Berkeley, CA, USA). To separate the medium containing the BVs from the cells containing the OBs, a low-speed centrifugation was performed at $2400 \times g$ during $5 \mathrm{~min}$. The supernatant sample containing the BVs was transferred to a $15 \mathrm{~mL}$ collection tube (Sample 1; S1). The pellet with the cells and OBs were rinsed twice with $1 \mathrm{~mL}$ phosphatase-buffered saline (PBS) pH 7.4 and resuspended in $1 \mathrm{~mL}$ PBS. OBs were released from cells by sonication in an ultrasonic bath (Selecta Master, JP Selecta, Abrera, Spain) for $10 \mathrm{~min}$ at maximum power $(100 \mathrm{~W})$ to produce sample 2 (S2). The lysate was then centrifuged at $5900 \times g$ for $5 \mathrm{~min}$. The pellet containing the cell debris and OBs was rinsed twice with $500 \mu \mathrm{L}$ of PBS and resuspended in $500 \mu \mathrm{L}$ PBS to produce sample 3 (S3). The supernatant containing the soluble phase of the infected cells was transferred to a $1.5 \mathrm{~mL}$ microcentrifuge tube to produce sample 4 (S4). The OBs produced in larvae and semi-purified by filtration through muslin and differential centrifugation $(2400 \times g$ during $5 \mathrm{~min}$ ) were also analyzed as sample 5 (S5). Three replicates were performed in parallel.

For each sample (S1-S5) and virus, an aliquot of $20 \mu \mathrm{L}$ was mixed with the same volume of $2 \times$ sample buffer (Bio-Rad, Berkeley, CA, USA), boiled at $100{ }^{\circ} \mathrm{C}$ for $5 \mathrm{~min}$, and then subjected to electrophoresis as previously described [30], using Criterion TGX ${ }^{\mathrm{TM}} 4-20 \%$ Precast Gel (Bio-Rad, Berkeley, CA, USA). Gels were stained with Coomassie Brilliant Blue R-250 (Bio-Rad, Berkely, CA, USA) and then distained in 30\% ethanol and 10\% acetic acid and photographed.

\subsection{Insect Bioassays}

To determine the insecticidal characteristics and the enhancement activity of BacPol$h E n 3$ recombinant OBs, insect bioassays were performed in second and fourth instar larvae of S. exigua. OBs originated from lysate cell culture and the OBs were produced in larvae. OBs from lysate cultures were used directly without any purification (OBs and cell medium), whereas those produced in larvae were purified by filtration and several rounds of centrifugation. Triplicate samples of OBs were counted in a Neubauer hemocytometer.

A discriminating concentration assay was initially performed using two concentrations of OBs for each instar. Second instars were inoculated with $2 \times 10^{4}$ and $2 \times 10^{5} \mathrm{OBs} / \mathrm{mL}$, whereas fourth instars were inoculated with $10^{5}$ and $10^{6} \mathrm{OBs} / \mathrm{mL}$ using the droplet feeding method [31]. Larvae were starved for 8 to $12 \mathrm{~h}$ at $25 \pm 1{ }^{\circ} \mathrm{C}$ and then allowed to drink from an aqueous suspension of OBs and $10 \%$ sucrose plus $0.001 \%(w / v)$ Fluorella Blue. Control 
larvae were treated identically but did not consume OBs. Groups of 28 larvae that ingested the suspension within 10 min were transferred individually to the wells of a 28-well plate with a piece of semi-synthetic formaldehyde-free diet [23]. Larvae were reared at $26 \pm 1{ }^{\circ} \mathrm{C}$ and mortality was recorded daily until insects had either died or pupated. Bioassays were performed five times (replicates) using different batches of larvae. Virus-induced mortality results were analyzed within each instar and each OB concentration, to compare the OBs from cell culture lysate with those purified from larvae. A Shapiro-Wilk test and Levene's test indicated that the data were normally distributed with homogeneity of variance. The results were then subjected to three-way analysis of variance (ANOVA) with virus (BacPh and $\mathrm{BacPhEn} 3$ ), origin (OBs + cell lysate and OBs from larva), and inoculum concentration (high and low) specified as factors. Means were compared by Tukey test. The analysis was performed in the R-based package Jamovi v.1.2.27.0 [32].

The pathogenicity of BacPhEn3 OBs produced in cell culture and in larvae was compared with that of BacPh OBs in concentration-mortality bioassays in second and fourth instars of S. exigua. Bioassays were performed following the droplet feeding method [31] to inoculate larvae with one of five concentrations of OBs. For second instars, the concentrations were $2 \times 10^{7}, 4 \times 10^{6}, 8 \times 10^{5}, 1.6 \times 10^{5}$ and $3.2 \times 10^{4} \mathrm{OBs} / \mathrm{mL}$, whereas for fourth instars, $1 \times 10^{8}, 1 \times 10^{7}, 1 \times 10^{6}, 1 \times 10^{5}$ and $1 \times 10^{4} \mathrm{OBs} / \mathrm{mL}$ were used to inoculate larvae. These concentrations were previously determined to kill between $95 \%$ and $5 \%$ of the experimental insects. Control larvae were treated identically but did not consume OBs. Groups of 28 larvae that ingested the suspension within $10 \mathrm{~min}$ were reared individually at $26 \pm 1{ }^{\circ} \mathrm{C}$ and mortality was recorded daily until insects had either died or pupated. The bioassay was performed three times using different batches of larvae. Virus-induced mortality results were subjected to probit analysis using the Polo-Plus program [33].

\section{Results}

\subsection{Recombinant BacPh and BacPhEn3 Virus DNAs}

The polyhedrin and enhancin 3 genes were amplified by PCR from AcMNPV C6 and TnGV DNAs, respectively, to obtain fragments of $1073 \mathrm{bp}$ and $2738 \mathrm{bp}$ (data not shown). Recombinant AcMNPV viruses that included the $p h$ gene ( $\mathrm{BacPh}$ ), and the $p h$ and $e n 3$ genes (BacPhEn3) were constructed using Bac-to-Bac technology. Correct insertion of these genes was confirmed by restriction endonuclease (REN) analysis (Figure 1a) and sequencing analysis following PCR amplification of adjacent regions using the M13-Fw and M13-Rv primers (Figure $1 b$ ).

(a)

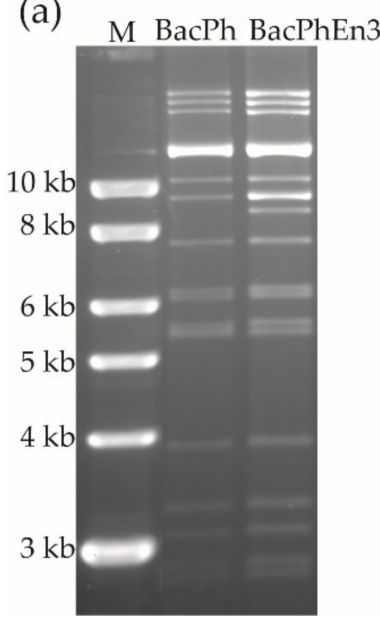

(b)

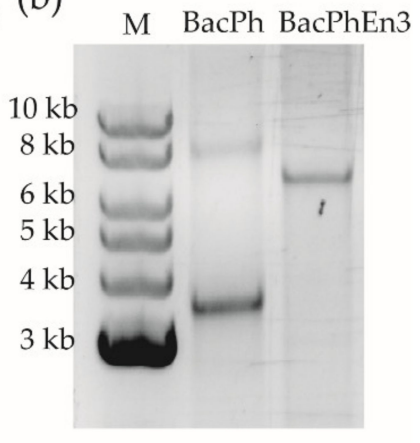

Figure 1. (a) PstI restriction endonuclease profiles of recombinant bacmids BacPh and BacPhEn3. The strong band above the $10 \mathrm{~Kb}$ marker corresponds to the Bac-to-Bac helper plasmid. (b) Inverted image of PCR products obtained after amplification of recombinant DNAs using M13-Fw and M13-Rv primers. The image was inverted for improved clarity. 
PCR amplicons of $\sim 3.5 \mathrm{~kb}$ and $\sim 6.5 \mathrm{~kb}$ for BacPh and BacPhEn3, respectively, were in line with the expected sizes of 3633 and $6371 \mathrm{bp}$ obtained after adding $2560 \mathrm{bp}$ to each of the PCR products following the Bac-to-Bac protocol (ThermoFisher Scientific, Waltham, MA, USA). In fact, the en 3 was a 2738 bp fragment, so the fragment obtained with BacPhEn3 DNA was $\sim 3 \mathrm{~kb}$ larger in the gel. Sequence analysis confirmed that the $p h$ gene in $\mathrm{BacPh}$ and BacPhEn3 recombinants and the en 3 in the BacPhEn3 recombinant were inserted correctly after the $p 10$ promoter and $p h$ promoter, respectively. DNA was then purified and transfected into Sf9 cells for the production of viral OBs.

\subsection{Transfection of Sf9 Cells with Recombinant BacPh and BacPhEn3 Virus DNAs}

At five days after transfection, most of the cells infected with BacPolhEn3 had OBs in the cell nuclei at levels similar to those of the control virus (BacPolh) and AcMNPV C6. Recombinant viruses produced normal OBs observable by optical microscopy (Figure 2a). The shape and size of OBs were indistinguishable among the three viruses (Figure 2a) and the ODV content (number of infectious units) of samples comprising $5 \times 10^{8}$ OBs did not differ significantly among these viruses (ANOVA, $F_{2,6}=0.919 ; p=0.449$ ) (Figure $2 b$ ).

(a)

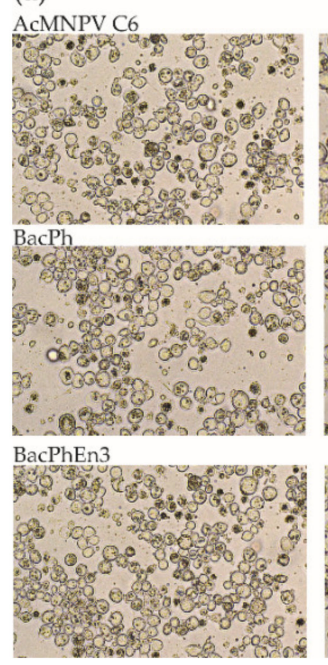

(b)

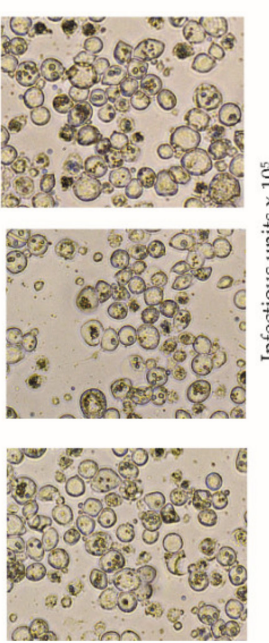

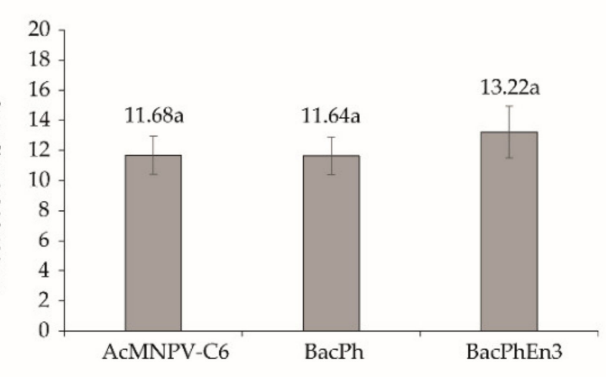

Figure 2. (a) Sf9 cells infected with AcMNPV-C6 BVs at 10 m.o.i., and Sf9 cells transfected with recombinant $\mathrm{BacPh}$ and $\mathrm{BacPhEn3}$. The images were taken 5 days after infection; on the left, low magnification $(40 \times)$ images of infected Sf9 cells and on the right, higher magnification $(100 \times)$ images of cells presenting normal presence and abundance of OBs in cell nuclei. (b) Results of end-point dilution assay of the ODVs released from samples of $5 \times 10^{8}$ OBs obtained from AcMNPV-C6 OBs and cell pellets of infected $\mathrm{BacPh}$ and $\mathrm{BacPhEn} 3$ cells showing similar numbers of infectious units (ANOVA, $p>0.05$ ). Values above columns indicate means. Error bars indicate standard deviation.

Examination of restriction endonuclease profiles and PCR analysis of recombinant OBs was performed to corroborate their identity in comparison with the original samples. Infected cells were recovered and lysed to obtain viral OBs, and DNA extraction was performed on these OBs. REN analyses showed that viral DNA profiles from BacPolh and BacPolhEn3 transfections (Figure 3a) were the same as those of the original inocula (shown in Figure 1a). M13-Fw and M13-Rv primers produced a PCR product of $\sim 3.5 \mathrm{~kb}$ and $\sim 6.5 \mathrm{~kb}$ for BacPh and BacPhEn3, respectively, which corresponded with the expected sizes (Figure 1b). Finally, sequence analysis confirmed the presence of these genes in the correct position, and that the recombinant viruses were correctly designed and constructed (data not shown). 
(a)

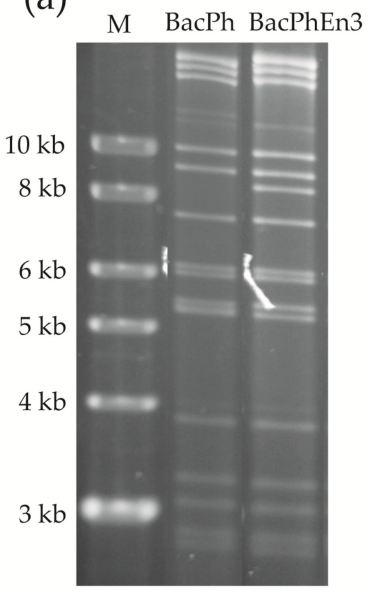

(b)

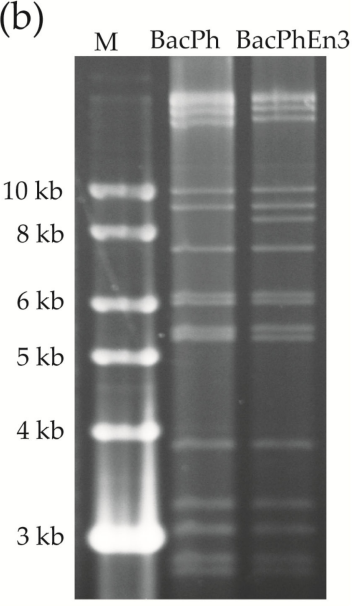

Figure 3. Restriction endonuclease profiles with PstI of (a) cell pellets transfected with recombinant bacmids BacPh and BacPhEn3, and (b) OBs purified from larvae after injection of transfection supernatant (BVs) in Spodoptera exigua fifth instars. The molecular size marker, M, was smart ladder (Stratagene).

\subsection{Production of BacPh and BacPhEn3 OBs in Larvae}

The supernatant containing BVs was used to inject $S$. exigua fifth instar larvae to produce large quantities of OBs. Injection of $\mathrm{BacPh}$ and $\mathrm{BacPhEn} 3 \mathrm{BV}$ resulted in a similar prevalence of larvae mortality (range 86-95\%). Dead larvae were collected five to seven days after infection and showed the typical signs of lethal polyhedrosis disease. OBs were purified and were checked by REN and PCR analysis. REN treatment of BacPh and $\mathrm{BacPhEn} 3 \mathrm{OBs}$ resulted in the characteristic profiles of each virus (Figure $3 \mathrm{~b}$ ), identical to those of the original inoculated viruses (shown in Figure 1a). Sequence analysis of PCR products confirmed that sequences were identical to those of the original inocula. Therefore, the BacPh and BacPhEn3 OBs produced in larvae were confirmed to be those of the recombinant viruses and were used for bioassays.

\subsection{Enhancin 3 Is Solubilized in the Cell Medium}

To detect En3, a sample separation protocol was followed (Figure 4a), and an aliquot of each sample was used to perform SDS-PAGE (Figure $4 b$ ).

The En3 protein was present in Sf9 cells transfected with the recombinant BacPhEn3 but was not present in BacPh transfected cells. The SDS-PAGE analysis revealed that the $\mathrm{BV}$ fraction (S1) presented a major band of $56.8 \mathrm{kDa}$, corresponding to the GP64 protein (indicated by the letter "a" in both BacPh and BacPhEn3; Figure $4 \mathrm{~b}$ ), and lacked the band corresponding to En3. Cell pellets resulting from infection with BacPhEn3 showed a band of $\sim 100 \mathrm{kDa}$ that corresponded in size to En3 (indicated by the letter " $\mathrm{c}$ " in S2 in BacPhEn3; Figure $4 \mathrm{~b}$ ), which was absent in the S2 sample of BacPh. A band of similar size to En3 was present in the S2 sample of $\mathrm{BacPh}$, but this had a lower molecular weight and also appeared below the En3 band in S2 of BacPhEn3 (indicated with an asterisk in S2 in both $\mathrm{BacPh}$ and BacPhEn3). Moreover, in $\mathrm{S} 4$ of BacPhEn3, only the upper band (labeled "a") was present, corresponding to En3, which co-migrated with En3 in S2 of BacPhEn3 (also labeled "a"), rather than the lower band (labeled "**) in S2 of BacPhEn3. 
(a)

$10^{6}$ Sf9 cells transfected with $1 \mu \mathrm{g}$ BacPh and BacPhEn3

$$
\begin{gathered}
\lfloor 5 \text { days post infection } \\
\text { Harvest cells and medium } \\
\text { Low speed centrifugation }
\end{gathered}
$$

Pellet resuspended in PBS containing cells and OBs

S2. OBs and soluble cell fraction (after cell lysis by sonication)

Low speed centrifugation

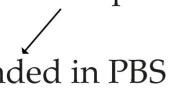

S3. Pellet resuspended in
Cells debris and OBs
S4. Supernatant Soluble phase of cells

\section{S1. Supernatant} containing BVs

OB production in larvae BVs injected into S. exigua larvae

S5. Purified OBs

(b)

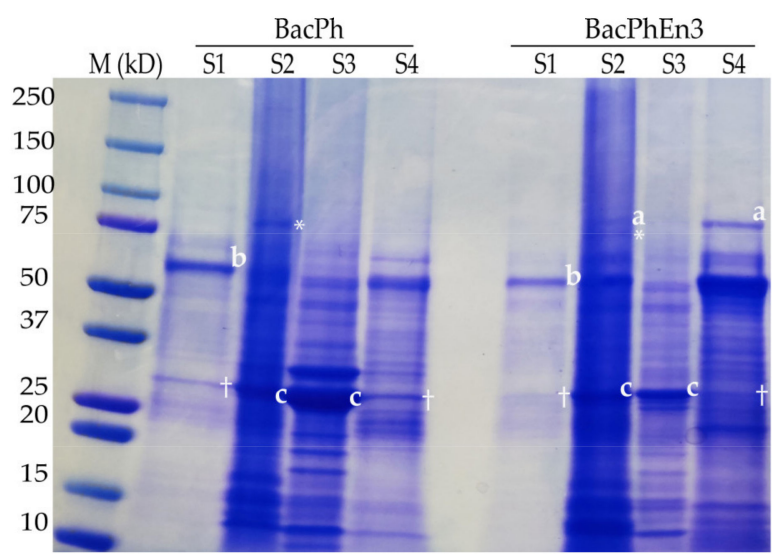

(c)

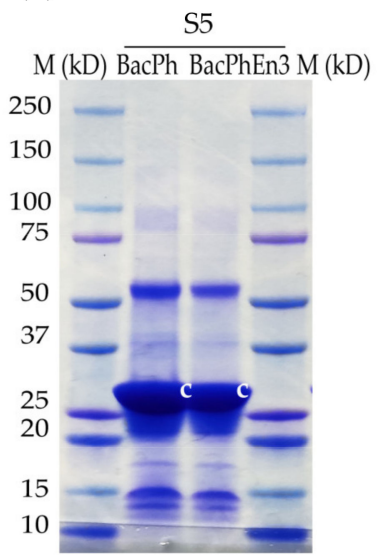

Figure 4. (a) Sample extraction protocol for virus-infected cells and OBs resulting in five types of samples (S1-S5). For each sample, a $20 \mu \mathrm{L}$ sample was subjected to SDS-PAGE. (b) SDS-PAGE of samples S1-S4 obtained from cell culture. Letters on gel image indicate (a) the En3 protein in S2 and S4 in BacPhEn3, (b) GP64 in S1 for both BacPh and BacPhEn3 and (c) the polyhedrin in S2, S3 and S5, for both BacPh and BacPhEn3. Signs on gel images indicate $(\dagger)$ the band similar to polyhedrin and $(*)$ the band immediately below the En3 protein in S2 in both BacPh and BacPhEn3. (c) SDS-PAGE of sample S5 purified from virus-killed larvae shown in (a). Letters on gel image indicate (c) the polyhedrin in S2, S3 and S5, for both BacPh and BacPhEn3.

Cell pellets were lysed by sonication and the pellet, and the supernatant obtained after low-speed centrifugation showed the band of $100 \mathrm{kDa}$ that corresponded in size to En3 (indicated with the letter " $c$ " in S4 in BacPhEn3; Figure 4b). As a control, cells infected with BacPh did not show the band corresponding to En3 in the supernatant of cell lysate (S4 sample in BacPh; Figure 4b). The purified OBs from lysed cells (S3) did not show the band corresponding to En3, indicating that this protein was not present in the OBs or ODVs at detectable quantities (S3 sample in BacPhEn3; Figure 4b). A band corresponding to En3 was not observed in the OBs purified from larvae and was therefore also not present in the ODVs at detectable levels (S5 sample; Figure 4c).

Finally, the polyhedrin protein of $27 \mathrm{kDa}$ was present in cell pellets and OBs produced in larvae infected by BacPh and BacPhEn3 (S2 and S3; Figure 4b and S5; Figure 4c), indicating the correct production of this OB protein, as expected. In the S4 samples of $\mathrm{BacPh}$ and BacPhEn3, a faint band of similar size to Polh was present (indicated with a cross in S4) but was clearly less intense than in S2 and S3. To separate the OBs (S3) and the 
soluble fraction of the cells (S4), a low-speed centrifugation was performed; therefore, the soluble fraction (S4) may have contained traces of OBs. It is also possible that this band could be another cellular protein, as it also appeared in the S1 sample (BV fraction) in both BacPh and BacPhEn3.

These results clearly indicated that En 3 was produced but was not incorporated into OBs or enveloped within ODVs, but instead accumulated in the cell medium as a soluble entity.

\subsection{Biological Activity of BacPhEn3 OBs Produced in Cell Culture and in Larvae}

Discriminating concentration insect bioassays were performed with the OBs and cell lysate from cell culture (equivalent to S2 in Figure 4a) and with OBs purified from larvae (equivalent to S5 in Figure 4a). In second instars (Figure 5a), a significant interaction effect was detected in virus $\times$ origin (cells or larvae) of OBs, presumably due to the presence of En3 in the cell lysate of BacPhEn3-infected cells $\left(F_{1,32}=5.460 ; p=0.026\right)$. The origin of the inoculum (cells vs. larvae) also interacted significantly with inoculum concentration $\left(F_{1,32}=6.982 ; p=0.013\right)$. The main effects of virus $\left(F_{1,32}=0.882 ; p=0.355\right)$ and inoculum origin $\left(F_{1,32}=0.058 ; p=0.812\right)$ were not significant, whereas mortality increased significantly with $\mathrm{OB}$ concentration, as expected $\left(F_{1,32}=214.71 ; p<0.001\right)$.

(a)

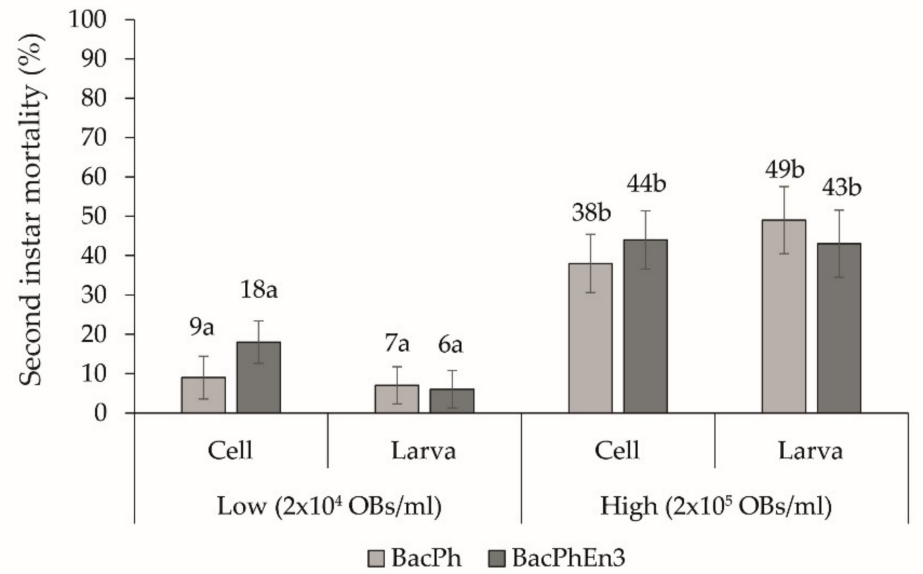

(b)

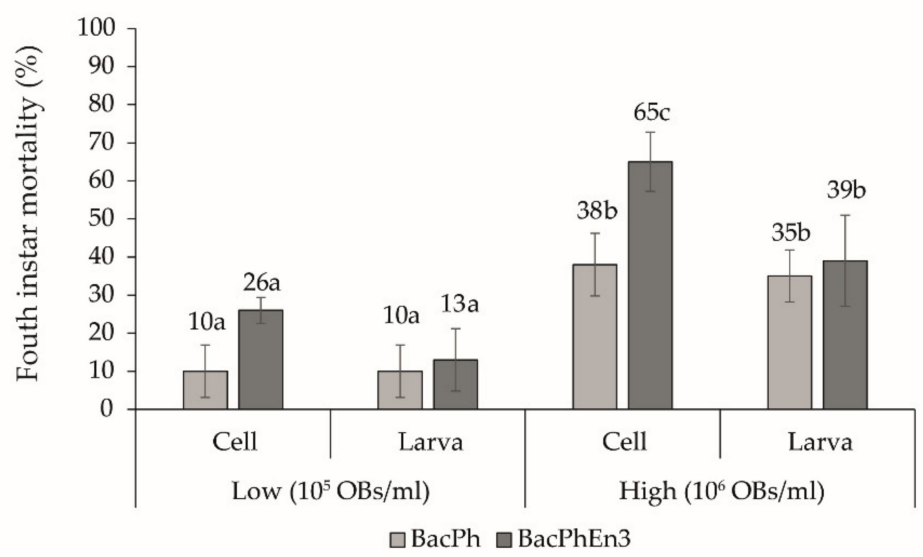

Figure 5. Percentage of larval mortality induced by $\mathrm{BacPh}$ and $\mathrm{BacPhEn} 3 \mathrm{OBs}$ produced in cell culture (OBs + cell lysate) and OBs purified from larvae in (a) second instars and (b) fourth instars of Spodoptera exigua. Second instars were inoculated with $2 \times 10^{4} \mathrm{OBs} / \mathrm{mL}$ or $2 \times 10^{5} \mathrm{OBs} / \mathrm{mL}$ and fourth instars with $10^{5} \mathrm{OBs} / \mathrm{mL}$ or $10^{6} \mathrm{OBs} / \mathrm{mL}$. Values above columns indicate mean percentage of mortality. Values followed by identical letters did not differ significantly (ANOVA, Tukey $p<0.05$ ). Error bars indicate SD. 
The results differed markedly in fourth instars compared to second instar larvae (Figure $5 b)$. The main effects of virus $\left(F_{1,32}=21.20 ; p<0.001\right)$, inoculum origin $\left(F_{1,32}=15.43\right.$; $p<0.001)$ and inoculum concentration $\left(F_{1,32}=122.54 ; p<0.001\right)$ significantly affected larval mortality. There was also a significant interaction of virus $\times$ origin of $\operatorname{OBs}\left(F_{1,32}=11.572\right.$; $p=0.002)$, due to the presence of Eh3 in the cell lysate of BacPhEn3 OBs + cell lysate, which resulted in the highest prevalence of mortality in the high inoculum concentration $(65 \%$, Figure 5b), and its presumed absence in BacPhEn3 OBs purified from larvae (39\% mortality). The tendency was the same in the low inoculum concentration, although the mortality induced by BacPh OBs and BacPhEn3 OBs did not differ significantly when inoculated in mixtures with infected cell lysate (Tukey, $p>0.05$ ). None of the other interaction terms were significant $(p>0.05)$.

As the discriminating concentration assays revealed that BacPhEn3 OBs + cell lysate resulted in high mortality in fourth instar larvae, a series of concentration-mortality response bioassays was performed. Specifically, the $\mathrm{LC}_{50}$ values and relative potencies of OBs were estimated for both recombinants obtained from cell culture and larvae based on the prevalence of virus-induced mortality observed across a range of five OB concentrations (Table 2).

Table 2. OB pathogenicity $\left(\mathrm{LC}_{50}\right)$ in Spodoptera exigua second and fourth instars inoculated with BacPh and BacPhEn3 OBs + cell lysate from infected Sf9 cells and BacPh and BacPhEn3 OBs purified from larvae following injection with BacPh and BacPhEn3 BVs.

\begin{tabular}{|c|c|c|c|c|c|c|c|c|}
\hline \multirow{2}{*}{ Instar } & \multirow{2}{*}{ Virus } & \multirow{2}{*}{ Slope \pm SE } & \multirow{2}{*}{$\begin{array}{c}L_{50} \\
(\mathrm{OBs} / \mathrm{mL})\end{array}$} & \multicolumn{2}{|c|}{ 95\% Conf. Interval } & \multirow{2}{*}{$\begin{array}{l}\text { Relative } \\
\text { Potency }\end{array}$} & \multicolumn{2}{|c|}{$95 \%$ Conf. Interva } \\
\hline & & & & Lower & Upper & & Lower & Upper \\
\hline \multirow{6}{*}{$\begin{array}{l}\text { Second } \\
\text { instar }\end{array}$} & \multicolumn{8}{|c|}{ OBs and cell lysate from Sf9 cells } \\
\hline & $\mathrm{BacPh}$ & $0.306 \pm 0.078$ & $1.33 \times 10^{5}$ & $4.30 \times 10^{4}$ & $8.75 \times 10^{5}$ & 1 & & \\
\hline & BacPhEn3 & $0.573 \pm 0.084$ & $4.51 \times 10^{4}$ & $2.37 \times 10^{4}$ & $8.73 \times 10^{4}$ & 2.95 & 1.03 & 11.40 \\
\hline & \multicolumn{8}{|c|}{ OBs purified from larvae following injection with BVs } \\
\hline & $\mathrm{BacPh}$ & $0.555 \pm 0.088$ & $1.15 \times 10^{5}$ & $5.93 \times 10^{4}$ & $2.58 \times 10^{5}$ & 1.16 & 0.27 & 5.03 \\
\hline & BacPhEn3 & $0.488 \pm 0.093$ & $2.03 \times 10^{5}$ & $8.73 \times 10^{4}$ & $7.52 \times 10^{5}$ & 0.65 & 0.13 & 3.33 \\
\hline \multirow{6}{*}{$\begin{array}{l}\text { Fourth } \\
\text { instar }\end{array}$} & \multicolumn{8}{|c|}{ OBs and cell lysate from Sf9 cells } \\
\hline & $\mathrm{BacPh}$ & $0.847 \pm 0.126$ & $1.10 \times 10^{6}$ & $6.15 \times 10^{5}$ & $2.84 \times 10^{6}$ & 1 & - & - \\
\hline & BacPhEn3 & $1.019 \pm 0.119$ & $2.34 \times 10^{5}$ & $1.66 \times 10^{5}$ & $3.53 \times 10^{5}$ & 4.69 & 2.63 & 10.59 \\
\hline & \multicolumn{8}{|c|}{ OBs purified from larvae following injection with BVs } \\
\hline & $\mathrm{BacPh}$ & $0.830 \pm 0.110$ & $1.09 \times 10^{6}$ & $6.38 \times 10^{5}$ & $2.14 \times 10^{6}$ & 1.01 & 0.40 & 2.07 \\
\hline & BacPhEn3 & $0.756 \pm 0.106$ & $1.13 \times 10^{6}$ & $6.32 \times 10^{5}$ & $2.37 \times 10^{6}$ & 0.97 & 0.37 & 2.02 \\
\hline
\end{tabular}

Relative potency values were calculated with respect to the BacPh OBs + cell lysate (control) treatment in both instars. Goodness-of-fit tests were non-significant for second $\left(\chi^{2}=6.82 ; \mathrm{df}=3 ; p=0.078\right)$ and fourth $\left(\chi^{2}=2.85 ; \mathrm{df}=3 ; p=0.416\right)$ instars.

In second instar larvae, the BacPhEn3 OBs + cell lysate were 2.95-fold more pathogenic than control BacPh OBs + cell lysate, presumably due to the presence of En3 in the lysate fraction. In contrast, $\mathrm{BacPh}$ and $\mathrm{BacPhEn} 3 \mathrm{OBs}$ purified from larvae were as pathogenic as the control virus with relative potency values of 1.16 and 0.65 , respectively, with broadly overlapping 95\% confidence limits, reflecting the absence of En3 in these samples.

The enhancement of infection of BacPhEn3 OBs + cell lysate was more marked in fourth instar larvae. The BacPhEn3 OBs + cell lysate was 4.69-fold more pathogenic than control BacPh OBs + cell lysate, whereas BacPh OBs and BacPhEn3 OBs purified from larvae were as pathogenic as the control BacPh OBs + cell lysate with a relative potency of 1.01 and 0.97, respectively. These findings confirmed that the lysate of BacPhEn3-infected cells was responsible for the potentiation of AcMNPV infection. 


\section{Discussion}

The localization of a granulovirus enhancin in NPV-infected Sf9 cells and its enhancing activity was investigated by constructing an AcMNPV recombinant that expressed the enhancin 3 (en3) gene of TnGV. The enhancin protein was localized to the soluble fraction of the cells and was not present in NPV OBs (or ODVs) in detectable quantities. Following cell lysis, the enhancing factor present in the lysate was capable of potentiating NPV infection by $\sim 3$-fold in second instars and $\sim 4$.7-fold in the fourth instar larvae of S. exigua.

These findings are consistent with the purification of enhancin from T. ni cells infected with recombinant AcMNPV that expressed the TnGV En3 reported by Lepore et al. [10]. In contrast, Hayakawa et al. [18] used intact virus infected Sf9 cells as inoculum. These cells were infected with a polyhedrin-negative AcMNPV recombinant virus that expressed the En 3 of TnGV, so that larvae in the bioassay ingested mixtures of wild-type AcMNPV OBs and cells infected by the recombinant virus that likely contained the enhancin protein. In another study, recombinant virus expressing the TnGV enhancin (En3) was subjected to three rounds of passage in cell culture prior to insect bioassay. The resulting OBs were observed to have modest levels (two-fold) of potentiation activity in a diet contamination bioassay, although the purification steps of the OBs were not described [19]. We assume that the OB preparations used by these authors included traces of enhancin from the host cells, which resulted in the modest levels of potentiation observed.

In the present study, we demonstrated that the lysate of infected cells contained the potentiation factor rather than the recombinant OBs or ODVs. The BacPhEn3 OBs purified from infected larvae by filtration and differential centrifugation were as pathogenic as control $\mathrm{BacPh}$ OBs purified from larvae or BacPh OBs inoculated in mixtures with cell lysate. Potentiation activity was only observed for BacPhEn3 OBs when in mixtures with the lysate of BacPhEn3-infected cells. The prevalence of virus-induced mortality could have been influenced by the presence of non-occluded virions in cells. If so, such entities would be present in both control (BacPh) and $\mathrm{BacPhEn} 3$ treatments involving cell lysate. In addition, the BV and OB titers obtained in infected cells were similar for the two viruses, suggesting similar titers of non-occluded virions in both $\mathrm{BacPh}$ and $\mathrm{BacPhEn} 3$ treatments. Therefore, we can conclude that the potentiation effect was due to the presence of En3 in the lysate of BacPhEn3-infected cells.

When purifying OBs from virus-killed insects, once the infected larvae had liquefied, they were homogenized and filtered to eliminate debris. The resulting suspension was subjected to various rounds of low-speed centrifugation to pellet the OBs, whereas the supernatant containing traces of cell debris and cellular proteins was discarded to finally obtain semi-purified OBs $[34,35]$. Therefore, any enhancing factor was eliminated or markedly reduced in concentration during OB purification from larvae. It is possible that bioassay results could have been influenced by the presence of non-occluded virions in cell lysates. However, if present, such entities would be present in similar quantities in both control $(\mathrm{BacPh})$ and $\mathrm{BacPhEn} 3$ treatments involving cell lysate, so we are confident that the effects attributed to the presence of enhancin are real and not an inadvertent effect of the presence of virions that had not been incorporated into OBs.

The enhancing activity demonstrated in this study ( $\sim$-fold and $\sim 4.7$-fold in second and fourth instars, respectively) was broadly in line with that reported by other authors [10,19], although Hayakawa et al. [18] reported higher potentiation of AcMNPV and SeMNPV infection in S. exigua third instars, for the reasons mentioned above. In other systems, a recombinant AcMNPV expressing the enhancing-like protein of AgseGV was fivefold more pathogenic than the wild-type OBs [36]. Using a fusion technology, the AgseGV enhancin and GP37 were embedded independently into two different recombinants, and the recombinant bacmid OBs were three- and fivefold more pathogenic than wild-type OBs, respectively [21]. The GP37 is homologous to the glycoprotein fusolin present in entomopoxvirus spindles, the N-terminal of which binds to chitin and markedly enhances infection by entomopoxviruses and nucleopolyhedroviruses [22]. Similarly, using the same technology, both AgseGV enhancin and GP37 were embedded in the same recombinant 
OBs that were 3.9-fold and 7.4-fold more pathogenic to second and fourth instar larvae than wild-type OBs, respectively [20].

We observed a clear instar-dependent effect in the potentiation activity of BacPhEn3 cell lysate. Enhancin potentiation tends to be greater in late instars that are normally more resistant to baculovirus infection than their younger counterparts $[4,12,20]$. The lepidopteran PM contains pores that vary in size among the different species and across larval instars [4]. In early instars, the PM is generally less tightly constructed and more permeable, whereas in later instars, the PM is well-formed and has lower porosity $[4,6,37]$. Therefore, PM disruption by these enzymes is greater in late instars and the potentiation effect more marked as late instar larvae are usually more resistant to baculovirus infection.

Enhancin orthologues are present in a few group II alphabaculoviruses [13-15,38,39]. These proteins are present within ODVs in association with nucleocapsids, where they appear to facilitate access to the midgut cells $[15,40]$. They also target IIM, with the mucins being common targets for both GV and NPV enhancins [40,41]. Indeed, GV and NPV enhancins are similar but differ in several aspects. They share up to $39 \%$ identity, range in size from 758 to $848 \mathrm{aa}$, and contain a conserved zinc-binding domain that is characteristic of metalloproteases [6,42]. However, NPV enhancins contain a potential transmembrane domain followed by a series of basic amino acid residues at their carboxyl terminus (Figure S1) [6]. The presence of this transmembrane domain allows them act as fusains targeted at midgut cells [6]. The absence of the transmembrane domain in granulovirus enhancins would prevent the envelopment of TnGV En3 in the AcMNPV ODV membrane. In contrast, NPV enhancins are able to insert into the ODV membrane of AcMNPV. For example, the Mamestra configurata NPV enhancin was found to be a component of the ODVs of a recombinant AcMNPV expressing this protein [40], and the recombinant OBs were over fourfold more pathogenic than wild-type OBs [14].

As GV and NPV enhancins clearly have different functions, the incorporation of a GV-type enhancin within alphabaculovirus OBs would appear challenging. This was recently achieved by fusion of the enhancin gene with the polyhedrin gene [20,21,43]. The application of gene fusion technology has the potential to create a novel protein expression system and an efficient virus-based system for insecticide production in countries that allow the use of genetically modified organisms in agriculture [44]. However, the use of recombinant viruses in agriculture is currently prohibited in many countries including those of the European Union (Directive 2001/18/CE).

\section{Conclusions}

In the present study, a granulovirus enhancin produced by an AcMNPV recombinant accumulated within infected cells and was shown to be present in the soluble fraction of the cells following lysis. The soluble fraction was responsible for potentiation of AcMNPV infection in S. exigua larvae and was more effective in fourth instars than in second instar larvae. The production of solubilized enhancins using a baculovirus-based expression systems could be used to improve the efficacy of biological insecticides against lepidopteran pests.

Supplementary Materials: The following are available online at https:/ /www.mdpi.com/article/10 $.3390 /$ v13071233/s1, Figure S1. Global alignment of enhancin proteins. The HEXXHX(8,28)E motif is represented with light green residues. The transmembrane helices are represented in red residues. The Peptidase_M60 Superfamily, the SslE_AcfD_Zn_LP and Mucin_bdg super family domains are shown in green, orange, and blue boxes, respectively.

Author Contributions: Conceptualization, A.R.-B., O.S. and P.C.; methodology, A.R.-B., O.S. and A.B.F.; validation, A.R.-B., O.S. and A.B.F.; formal analysis, A.R.-B., O.S. and T.W., investigation, A.R.-B., O.S., A.B.F., T.W. and P.C., resources, P.C., data curation, A.R.-B., O.S., A.B.F. and T.W., writing-original draft preparation A.R.-B., O.S. and A.B.F.; writing-review and editing, T.W. and P.C.; visualization, A.R.-B., O.S. and A.B.F.; supervision, T.W. and P.C.; project administration, P.C.; funding acquisition, P.C. All authors have read and agreed to the published version of the manuscript. 
Funding: This study received financial support from the Spanish Ministry project AGL2017-83498C2-1-R. Bioinsectis SL funded the activities of ABF.

Institutional Review Board Statement: Not applicable.

Informed Consent Statement: Not applicable.

Acknowledgments: We thank Noelia Gorria, Itxaso Ibáñez and Amaia Redín (UPNA, Spain) for technical assistance and insect rearing.

Conflicts of Interest: The authors declare no conflict of interest. The funders had no role in the design of the study; in the collection, analyses, or interpretation of data; in the writing of the manuscript, or in the decision to publish the results.

\section{Appendix A}

To select a suitable enhancin for the construction of the recombinant virus, a literature survey was carried out to identify the betabaculovirus enhancins with the highest potentiation activity.

The potentiation activity of betabaculovirus enhancins has been extensively studied. In contrast, NPV enhancins are present only in a few NPVs and their location within the ODVs $[15,40]$ hinders their purification and has restricted their study as synergists of viral infection.

In an early study, a factor present in Pseudaletia unipuncta (Psun) GV was observed to increase the infectivity of PsunNPV OBs in mixed infections [45]. Later, Granados et al. demonstrated that the enhancin from TnGV degraded major glycoproteins within the PM [1,10]. To date, the enhancins of Agrotis segetum (Agse), Epinotia aporema (Epap), Helicoverpa armigera (Hear), Spodoptera frugiperda (Sf), Trichoplusia ni (Tn), Pseudaletia unipuncta (Psun) and Xestia c-nigrum (Xecn) GVs have been demonstrated to enhance baculovirus infections $[8,9,17,20,46,47]$. Enhancins from TnGV have been the most frequent subject of study. Enhancement activity has been demonstrated by different approaches, particularly the use of enhancins purified from GV granules [3,7,10,12]. They have been assayed in mixtures with NPV OBs [18,46,47] by constructing recombinant baculoviruses [18-21] or transgenic plants expressing enhancin genes [48,49].

Among the different enhancin species, the TnGV enhancins produced the highest enhancement of baculovirus infections [7,12]. Reports of enhanced infection by AcMNPV in mixtures with purified TnGV enhancins vary from a 60 to $63 \%$ increase in T. $n i[7,10]$ to $82 \%$ in Pseudaletia unipuncta [12,17]. Using recombinant viruses expressing the TnGV enhancin, the pathogenicity of NPV OBs increased 39-fold for S. exigua larvae inoculated with AcMNPV, or 10-fold for larvae inoculated with SeMNPV [18]. Larvae with a diet based on transgenic plants or mixtures of OBs and transgenic tobacco expressing enhancin showed increased susceptibility to infection $[48,49]$. The delta-endotoxins of Bacillus thuringiensis were also more effective when formulated with TnGV enhancin [50,51]. Taken together, these findings led us to select TnGV enhancins for our study. These proteins were also subjected to a molecular analysis (Appendix B) to identify the presence of active domains.

\section{Appendix B}

A protein analysis was performed to identify the presence of active domains in TnGV enhancins. Three enhancins have been identified in the genome [16], and a conserved domain search was performed with NBCI batch Web CD-Search Tool [52] in order to select one to construct the recombinant AcMNPV. De novo discovery of motifs was carried out using MEME suite [53]. TMHMM Server v. 2.0 was used to predict transmembrane helices in proteins [54,55]. Protein properties were identified using the Protein Molecular Weight Calculator available online: http:/ / www.sciencegateway.org/tools/proteinmw.htm (accessed on 19 May 2021). Enhancin protein sequences included in the analysis are available in the NCBI GenBank database under accession numbers: YP_002268112.1 (AgipNPV_En), YP_009513096.1 (AgseGV_En), AAP29820.1 (CfMNPV_En), AAG33872.1 (ChfuGV_En 
AAG33872.1), AFP66947.1 (DekiNPV_En), YP_001649133.1 (HearGV_En1), YP_001649134.1 (HearGV_En2), YP_001649135.1 (HearGV_En3), YP_001649146.1 (HearGV_En4), NP_047702.1 (LdMNPV_En1), NP_047797.1 (LdMNPV_En2), AAM09197.1 (MacoNPVA_En), NP_689263.1 (Maco_NPV-B_En), ACU46624.1 (MbMNPV_PEn), YP_009249965.1 (MolaGV_En3), YP_009249970.1 (MolaGV_En4), YP_009666739.1 (MyunNPV_En), YP_009345853.1 (MyunGV_En2), AUA60360.1 (OpbrNPV_En), YP_009049908.1 (PespNPV_En), YP_003422496.1 (PsunGV_En1), YP_003422498.1 (PsunGV_En3), YP_003422509.1 (PsunGV_En4), AXS01151.1 (SfGV_En1), YP_009506217.1 (TnGV_En1), YP_009506219.1 (TnGV_En3), YP_009506228.1 (TnGV_En4), NP_059298.1 (XecnGV_Orf150), NP_059300.1 (XecnGV_Orf152), NP_059302.1 (XecnGV_Orf154) and NP_059314.1 (XecnGV_Orf166).

The en1, en3, and en4 enhancin genes from TnGV have open reading frames of $2487 \mathrm{bp}, 2706 \mathrm{bp}$, and $2574 \mathrm{bp}$, and encode proteins of 828, 901, and 857 amino acids with a molecular weight of 91, 100, and $95 \mathrm{kDa}$, respectively. Pairwise identities among the three enhancins were less than $32 \%$. Differences in amino acids sequences altered the predicted conserved domain sequences and the predicted transmembrane helices present in each enhancin protein (Figure S1). Within En3, the zinc metallopeptidase motif (HEXXHX $(8,28) \mathrm{E})$ (indicated by light-green residues in Figure S1) is present in the Peptidase_M60 Superfamily domain (marked in a green box in Figure S1), as in almost all metalloproteases [42]. In contrast, En1 and En4 lack this motif. The Mucin_bdg super family domain, putative mucin, or carbohydrate binding domain for the substrates of enhancin (inside blue box in Figure S1) and other similar metallopeptidases are present in En3 and En4 proteins and closely related enhancin proteins. Interestingly, the Peptidase_M60 Superfamily domain and transmembrane helices (marked in red text in Figure S1) are absent in En1, En3, and En4 proteins and closely related enhancins. In contrast to NPV enhancins, GV enhancins do not possess the transmembrane helix domains necessary for insertion in the ODV envelope (Figure S1).

\section{References}

1. Derksen, A.C.G.; Granados, R.R. Alteration of a lepidopteran peritrophic membrane by baculoviruses and enhancement of viral infectivity. Virology 1988, 167, 242-250. [CrossRef]

2. Wang, M.; Wang, J.; Yin, F.; Tan, Y.; Deng, F.; Chen, X.; Jehle, J.A.; Vlak, J.M.; Hu, Z.; Wang, H. Unravelling the entry mechanism of baculoviruses and its evolutionary implications. J. Virol. 2014, 88, 2301-2311. [CrossRef] [PubMed]

3. Wang, P.; Granados, R.R. An intestinal mucin is the target substrate for a baculovirus enhancin. Proc. Natl. Acad. Sci. USA 1997, 94, 6977-6982. [CrossRef] [PubMed]

4. Wang, P.; Granados, R.R. Molecular structure of the peritrophic membrane (PM): Identification of potential PM target sites for insect control. Arch. Insect Biochem. Physiol. 2001, 47, 110-118. [CrossRef]

5. Wang, M.; Hu, Z. Cross-talking between baculoviruses and host insects towards a successful infection. Philos. Trans. R. Soc. B 2019, 374, 20180324. [CrossRef] [PubMed]

6. Erlandson, M.A.; Toprak, U.; Hedegus, D.D. Role of the peritrophic matrix in insect-pathogen interactions. J. Insect Physiol. 2019, 117, 103894. [CrossRef]

7. Gallo, L.G.; Corsaro, B.G.; Hughes, P.R.; Granados, R.R. In vivo enhancement of baculovirus infection by the viral enhancing factor of a granulosis virus of the cabbage looper Trichoplusia ni (Lepidoptera: Noctuidae). J. Invertebr. Pathol. 1991, 58, 203-210. [CrossRef]

8. Gijzen, M.; Röelvink, P.; Granados, R. Characterization of viral enhancing activity from Trichoplusia ni granulosis virus. J. Invertebr. Pathol. 1995, 65, 289-294. [CrossRef]

9. Guo, H.F.; Fang, J.C.; Wang, J.P.; Zhong, W.F.; Liu, B.S. Interaction of Xestia c-nigrum granulovirus with peritrophic matrix and Spodoptera litura nucleopolyhedrovirus in Spodoptera litura. J. Econ. Entomol. 2007, 100, 20-25. [CrossRef]

10. Lepore, L.S.; Roelvink, P.R.; Granados, R.R. Enhancin, the granulosis virus protein that facilitates nucleopolyhedrovirus (NPV) infections, is a metalloprotease. J. Invertebr. Pathol. 1996, 68, 131-140. [CrossRef]

11. Tanada, Y.; Himeno, M.; Omi, E.M. Isolation of a factor, from the capsule of a granulosis virus, synergistic for a nuclearpolyhedrosis virus of the armyworm. J. Invertebr. Pathol. 1973, 21, 31-90. [CrossRef]

12. Wang, P.; Hammer, D.A.; Granados, R.R. Interaction of Trichoplusia ni granulosis virus-encoded enhancin with the midgut epithelium and peritrophic membrane of four lepidopteran insects. J. Gen. Virol. 1994, 75, 1961-1967. [CrossRef]

13. Bischoff, D.S.; Slavicek, J.M. Molecular analysis of an enhancin gene in the Lymantria dispar nuclear polyhedrosis virus. J. Virol. 1997, 71, 8133-8140. [CrossRef] 
14. Li, Q.; Li, L.; Moore, K.; Donly, C.; Theilmann, D.A.; Erlandson, M. Characterization of Mamestra configurata nucleopolyhedrovirus enhancin and its functional analysis via expression in an Autographa californica M nucleopolyhedrovirus recombinant. J. Gen. Virol. 2003, 84, 123-132. [CrossRef]

15. Slavicek, J.M.; Popham, H.J.R. The Lymantria dispar nucleopolyhedrovirus enhancins are components of occlusion-derived virus. J. Virol. 2005, 79, 10578-10588. [CrossRef]

16. Bivian-Hernández, M.A.; López-Tlacomulco, J.; Mares-Mares, E.; Ibarra, J.E.; Del Rincón-Castro, M.C. Genomic analysis of a Trichoplusia ni betabaculovirus (TnGV) with three different viral enhancing factors and two unique genes. Arch. Virol. 2017, 162, 3705-3715. [CrossRef]

17. Tanada, Y.; Hess, R.T.; Omi, E.M. Invasion of a nuclear polyhedrosis virus in midgut of the armyworm, Pseudaletia unipuncta, and the enhancement of a synergistic enzyme. J. Invertebr. Pathol. 1975, 26, 99-104. [CrossRef]

18. Hayakawa, T.; Shimojo, E.I.; Mori, M.; Kaido, M.; Furusawa, I.; Miyata, S.; Sano, Y.; Matsumoto, T.; Hashimoto, Y.; Granados, R. Enhancement of baculovirus infection in Spodoptera exigua (Lepidoptera: Noctuidae) larvae with Autographa californica nucleopolyhedrovirus or Nicotiana tabacum engineered with a granulovirus enhancin gene. Appl. Entomol. Zool. 2000, 35, 163-170. [CrossRef]

19. Del Rincón-Castro, M.C.; Ibarra, J.E. Effect of a nuclepolyhedrovirus of Autographa californica expressing the enhancin gene of Trichoplusia ni granulovirus on T. ni larvae. Biocontrol Sci. Technol. 2005, 15, 701-710. [CrossRef]

20. Lei, C.; Yang, S.; Lei, W.; Nyamwasa, I.; Hu, J.; Sun, X. Displaying enhancing factors on the surface of occlusion bodies improves the insecticidal efficacy of a baculovirus. Pest Manag. Sci. 2020, 76, 1363-1370. [CrossRef]

21. Yang, S.; Zhao, L.; Ma, R.; Fang, W.; Hu, J.; Lei, C.; Sun, X. Improving baculovirus infectivity by efficiently embedding enhancing factors into occlusion bodies. Appl. Environ. Microbiol. 2017, 83, e00595-17. [CrossRef] [PubMed]

22. Takemoto, Y.; Mitsuhashi, W.; Murakami, R.; Konishi, H.; Miyamato, K. The N-terminal region of an entomopoxvirus fusolin is essential for the enhancement of peroral infection, whereas the C-Terminal region is eliminated in digestive juice. J. Virol. 2008, 82, 12406-12415. [CrossRef] [PubMed]

23. Greene, G.L.; Leppa, N.; Dickerson, W.A. Velvetbean caterpillar: A rearing procedure and artificial medium. J. Econ. Entomol. 1976, 69, 487-488. [CrossRef]

24. King, L.A.; Possee, R.D. The Baculovirus Expression System. A Laboratory Guide; Chapman \& Hall: London, UK, 1992.

25. Ayres, M.D.; Howard, S.C.; Kuzio, J.; López-Ferber, M.; Possee, R.D. The complete DNA sequence of Autographa californica nuclear polyhedrosis virus. Virology 1994, 202, 586-605. [CrossRef]

26. Luckow, V.A.; Lee, C.; Barry, G.F.; Olins, P.O. Efficient generation of infectious recombinant baculoviruses by site-specific transposon-mediated insertion of foreign genes into a baculovirus genome propagated in Escherichia coli. J. Virol. 1993, 67, 4566-4579. [CrossRef]

27. Booth, W.T.; Schlachter, C.R.; Pote, S.; Ussin, N.; Mank, N.J.; Klapper, V.; Offermann, L.R.; Tang, C.; Hurlburt, B.K.; Chruszcz, M. Impact of an N-terminal polyhistidine Tag on protein thermal stability. ACS Omega 2018, 3, 760-768. [CrossRef]

28. Galloway, C.S.; Wang, P.; Winstanley, D.; Jones, I.M. Comparison of the bacterial Enhancin-like proteins from Yersinia and Bacillus spp. with a baculovirus Enhancin. J. Invertebrt. Pathol. 2005, 90, 134-137. [CrossRef]

29. O'Reilly, D.R.; Miller, L.K.; Luckow, V.A. Baculovirus Expression Vectors. A Laboratory Manual; Oxford University Press: New York, NY, USA, 1994.

30. Laemmli, U.K. Cleavage of structural proteins during the assembly of the head of bacteriophage T4. Nature 1970, 227, 680-685. [CrossRef]

31. Hughes, P.R.; Wood, H.A. A synchronous per oral technique for the bioassay of insect viruses. J. Invertebr. Pathol. 1981, 37, 154-159. [CrossRef]

32. Jamovi. Jamovi Statistical Software v.1.2.27.0. Available online: https://www.jamovi.org (accessed on 15 September 2020).

33. LeOra Software. POLO-PC: A User's Guide to Probit or Logit Analysis; LeOra Software: Berkeley, CA, USA, 1987.

34. Durantel, D.; Croizier, L.; Ayres, M.D.; Croizier, G.; Possee, R.D.; López-Ferber, M. The pnk/pnl gene (ORF 86) of Autographa californica nucleopolyhedrovirus is a nonessential, immediate early gene. J. Gen. Virol. 1998, 79, 629-637. [CrossRef]

35. Simón, O.; Williams, T.; López-Ferber, M.; Caballero, P. Genetic structure of a Spodoptera frugiperda nucleopolyhedrovirus population: High prevalence of deletion genotypes. Appl. Environ. Microbiol. 2004, 70, 5579-5588. [CrossRef]

36. Zhang, X.X.; Liang, Z.P.; Chen, X.H.; Song, X.F.; Wang, L.W.; Shao, X.F. Expression and synergistic function of enhancin-like gene of Agrotis segetum granulovirus. Chin. J. Virol. 2012, 28, 258-264.

37. Peng, J.; Zhong, J.; Granados, R.R. A baculovirus enhancin alters the permeability of a mucosal midgut peritrophic matrix from lepidopteran larvae. J. Insect Physiol. 1999, 45, 159-166. [CrossRef]

38. Popham, H.J.R.; Bischoff, D.S.; Slavicek, J.M. Both Lymantria dispar nucleopolyhedrovirus enhancin genes contribute to viral potency. J. Virol. 2001, 75, 8639-8648. [CrossRef]

39. Thiem, S.M. Baculovirus genes affecting host function. In Vitro Cell. Dev. Biol. Anim. 2009, 45, 111-126. [CrossRef]

40. Toprak, U.; Harris, S.; Baldwin, D.; Theilmann, D.; Gillot, C.; Hedegus, D.D.; Erlandson, M.A. Role of enhancin in Mamestra configurata nucleopolyhedrovirus virulence: Selective degradation of host peritrophic matrix proteins. J. Gen. Virol. 2012, 93, 744-753. [CrossRef] 
41. Shi, X.; Chamankhah, M.; Visal-Shah, S.; Hemmingsen, S.M.; Erlandson, M.; Braun, L.; Alting-Mees, M.; Khachatourians, G.G.; O'Grady, M.; Hedegus, D.D. Modeling the structure of the Type I peritrophic matrix: Characterization of a Mamestra configurata intestinal mucin and a novel peritrophin containing 19 chitin binding domains. Insect Biochem. Mol. Biol. 2004, 34, 1101-1115. [CrossRef]

42. Slavicek, J.M. Baculovirus enhancins and their role in viral pathogenicity. In Molecular Virology; Adoga, M.P., Ed.; InTech: Rijeka, Croatia, 2012; pp. 147-168.

43. Je, Y.H.; Jin, B.B.; Park, H.W.; Roh, J.Y.; Chang, J.H.; Seo, S.J.; Olszewski, D.R.; O’Reilly, D.R.; Kang, S.K. Baculovirus expression vectors that incorporate the foreign protein into viral occlusion bodies. Biotechniques 2003, 34, 81-87. [CrossRef]

44. Sun, X. History and current status of development and use of viral insecticides in China. Viruses 2015, 7, 306-319. [CrossRef]

45. Tanada, Y. Synergism between two viruses of the armyworm, Pseudaletia unipuncta (Haworth) (Lepidoptera, Noctuidae). J. Insect Pathol. 1959, 1, 215-231.

46. Biedma, M.E.; Salvador, R.; Ferrelli, M.L.; Sciocco-Cap, A.; Romanowski, V. Effect of the interaction between Anticarsia gemmatalis multiple nucleopolyhedrovirus and Epinotia aporema granulovirus, on Anticarsia gemmatalis (Lepidoptera: Noctuidae) larvae. Biol. Control 2015, 91, 17-21. [CrossRef]

47. Jeyarani, S.; Karuppuchamy, P. Investigations on the enhancing efficacy of granulovirus on nucleopolyhedrovirus of Helicoverpa armigera (Hübner). J. Biopestic. 2010, 3, 172-176.

48. Cao, J.; Ibrahim, H.; Garcia, J.J.; Mason, H.; Granados, R.R.; Earle, E.D. Transgenic tobacco plants carrying a baculovirus enhancin gene slow the development and increase the mortality of Trichoplusia ni larvae. Plant Cell Rep. 2002, 21, $244-250$.

49. Mori, M.; Kitamura, H.; Kondo, A.; Dohi, K.; Mori, M.; Kaido, M.; Mise, K.; Shimojyo, E.; Hashimoto, Y. Expression of an enhancin gene from the Trichoplusia ni granulosis virus confers resistance to lepidopterous insect pests to rice. Plant Biotechnol. 2006, 23, 55-61. [CrossRef]

50. Granados, R.R.; Fu, Y.; Corsaro, B.; Hughes, P.R. Enhancement of Bacillus thuringiensis toxicity to lepidopterous species with the enhancin from Trichoplusia ni granulovirus. Biol. Control 2001, 20, 153-159. [CrossRef]

51. Guo, W.; Kain, W.; Wang, P. Effects of disruption of the peritrophic membrane on larval susceptibility to Bt toxin Cry1Ac in cabbage loopers. J. Insect Physiol. 2019, 117, 103897. [CrossRef]

52. Marchler-Bauer, A.; Bryant, S.H. CD-Search: Protein domain annotations on the fly. Nucleic Acids Res. 2004, 32, 327331. [CrossRef] [PubMed]

53. Bailey, T.L.; Boden, M.; Buske, F.A.; Frith, M.; Grant, C.E.; Clementi, L.; Ren, J.; Li, W.W.; Noble, W.S. MEME Suite: Tools for motif discovery and searching. Nucleic Acids Res. 2009, 37, 202-208. [CrossRef] [PubMed]

54. Sonnhammer, E.L.; von Heijne, G.; Krogh, A. A hidden Markov model for predicting transmembrane helices in protein sequences. In Proceedings of the Sixth International Conference on Intelligent Systems for Molecular Biology, Montreal, QC, Canada, 28 June-1 July 1998; Glasgow, J., Littlejohn, T., Major, F., Lathrop, R., Sankoff, D., Sensen, C., Eds.; AAAI Press: Menlo Park, CA, USA, 1998; pp. 175-182.

55. Krogh, A.; Larsson, B.; von Heijne, G.; Sonnhammer, E.L.L. Predicting transmembrane protein topology with a hidden markov model: Application to complete genomes. J. Mol. Biol. 2001, 19, 567-580. [CrossRef] [PubMed] 